\title{
Rupture of non-communicating rudimentary uterine horn at 16 weeks of gestation
}

\author{
Renu Gupta*, Neena Gupta, Seema Dwivedi, Pavika Lal, Monica Chauhan
}

Department of Obstetrics \& Gynecology, GSVM Medical College, Kanpur, U.P., India

Received: 19 January 2014

Accepted: 02 February 2014

\author{
*Correspondence: \\ Dr. Renu Gupta, \\ E-mail: chauhanmonica290@gmail.com
}

(C) 2014 Gupta R et al. This is an open-access article distributed under the terms of the Creative Commons Attribution Non-Commercial License, which permits unrestricted non-commercial use, distribution, and reproduction in any medium, provided the original work is properly cited.

\begin{abstract}
Pregnancy in non-communicating rudimentary horn is extremely rare and the usual presentation is rupture of rudimentary horn in second trimester of pregnancy resulting in severe haemoperitoneum which can be life threatening. We report a case of ruptured rudimentary horn pregnancy in 23 years old G2P0A1Lo whose diagnosis was initially missed by ultrasonography and presented to us in hemorrhagic shock. Exploratory laparotomy revealed ruptured rudimentary horn pregnancy at 16 weeks with haemoperitoneum and excision of ruptured left rudimentary horn with ipsilateral salpingectomy was done.
\end{abstract}

Keywords: Non communicating rudimentary horn, Life threatening hemorrhagic shock

\section{INTRODUCTION}

Pregnancy in rudimentary uterine horn is a very rare entity with reported figures in literature between 1:76,000 and 1:140,000 pregnancies. ${ }^{1}$ The rudimentary horn may or may not have a functional cavity which can be communicating or non-communicating. It is usually associated with endometriosis and obstetrical complications like miscarriage, ectopic pregnancy, uterine rupture, preterm labour and malpresentations. Urinary anomalies are found in $30 \%$ of cases. ${ }^{2}$

\section{CASE REPORT}

A 23 years old woman G2P0A1Lo presented with history of amenorrhea of 4 months along with complaints of vomiting, diarrhea and mild pain in lower abdomen for last 2 days. On admission her vitals were stable with mild tenderness over lower abdomen and uterus was 16-18 weeks size with no history of bleeding per vaginum. She was managed conservatively. Resident on duty performed an emergency ultrasound and reported 16 weeks live pregnancy. Next day, she complained of acute abdominal pain and her general condition deteriorated very rapidly. She was extremely pale, pulse was $130 / \mathrm{min}$, thready, systolic blood pressure was $80 \mathrm{~mm} \mathrm{Hg}$, respiratory rate of $36 /$ min with abdominal tenderness, guarding and rigidity.

Bimanual pelvic examination revealed soft cervix and uterus size could not be made out, with full fornices. An immediate ultrasound was performed which revealed free fluid and a fetus with no cardiac activity with normal sized uterus maintaining its contour. Emergency laparotomy was performed. Intraoperatively hemoperitoneum of $3000 \mathrm{cc}$. blood along with dead fetus of about 16 weeks gestation was found in abdominal cavity with rupture of left rudimentary horn.

Excision of ruptured non-communicating rudimentary horn with left sided salpingectomy was performed. She made an uneventful recovery with 5 units of blood transfusion and was discharged in satisfactory condition. An ultrasound of renal system was done postoperatively which showed no abnormality. 


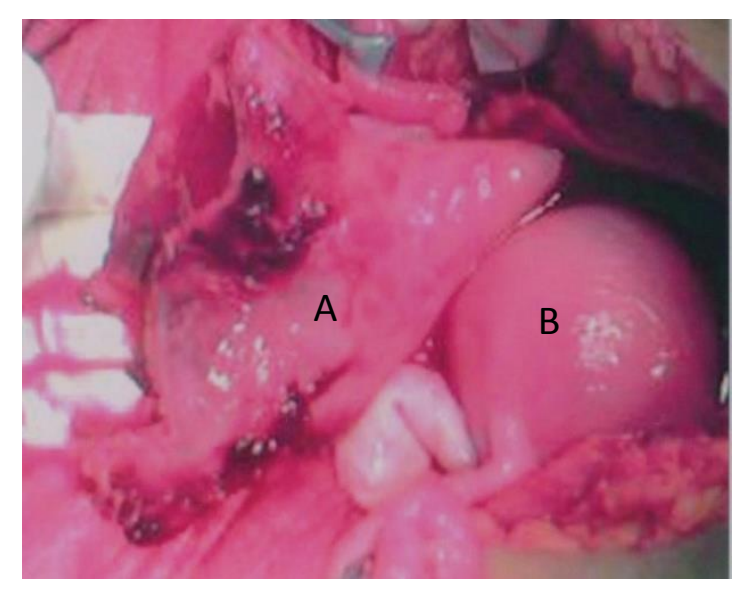

Figure 1: (A) Ruptured left rudimentary horn (B) Normal intact uterus.

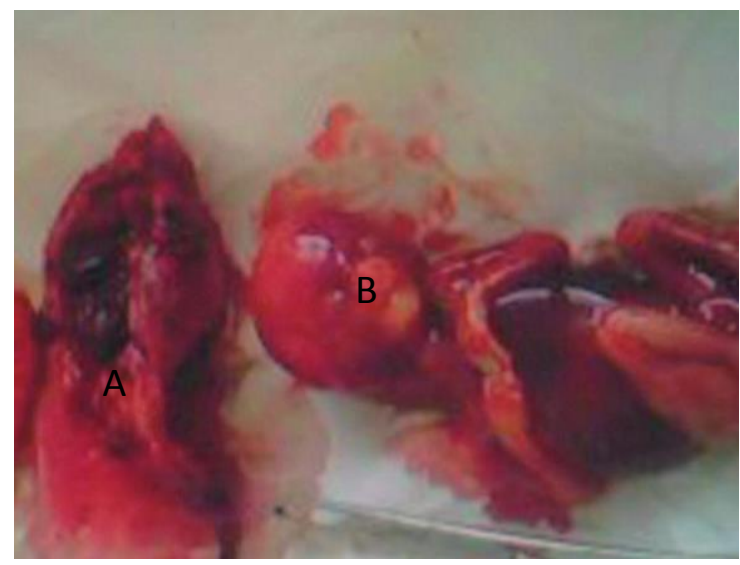

Figure 2: (A) Rudimentary horn (B) Foetus of 16 week gestation.

\section{DISCUSSION}

Pregnancy in the rudimentary uterine horn occurs either from small communication of uterine cavity or by transperitoneal migration of fertilized ovum from contra lateral side and the usual outcome is rupture of rudimentary horn before 20 weeks. ${ }^{3}$ Fedelle L had reported that ultrasonography is a useful tool in determining the presence of rudimentary horn but sensitivity of USG is around $26 \%$ and decreases with advancing pregnancy. ${ }^{4}$ Diagnosis is only by suspicion and excision of rudimentary horn is advisable. In our case the patient was admitted with nonspecific complaints but in due course she presented with acute abdomen and shock because of life threatening bleeding from the ruptured rudimentary horn.

\section{CONCLUSIONS}

Though rupture of rudimentary horn is one of the rare causes of acute abdomen but missing the diagnosis can lead to life threatening massive intraperitoneal haemorrhage and therefore timely diagnosis is essential in reducing the maternal morbidity and mortality.

\section{Funding: No funding sources \\ Conflict of interest: None declared \\ Ethical approval: Not required}

\section{REFERENCES}

1. Nahum GG. Rudimentary uterine horn pregnancy: a case report on surviving twins delivered eight days apart. Repord Med. 1997;42:525-32.

2. Jaya Singhe Y, Rane A, Stalewski H, Gravier S. The presentation and early diagnosis of Rudimentary uterine horn. Obstet Gynaecol. 2005;105:1456-67.

3. Goel P, Aggarwal A, Devi K, Takkar N, Saha PK, Huria A. Unicornuate uterus with noncommunicating rudimentary horn- different clinical presentations, J Obstet Gynaecol. 2005;55:155-8.

4. Fedelle L, Docta M, Verrellini P, et al. Ultrasound in the diagnosis of sub classes of unicornuate uterus. Obstet Gynaecol. 1988;71(2):274.

DOI: $10.5455 / 2320-1770 . i j r \operatorname{cog} 20140359$

Cite this article as: Gupta R, Gupta N, Dwivedi S, Lal P, Chauhan M. Rupture of non-communicating rudimentary uterine horn at 16 weeks of gestation. Int J Reprod Contracept Obstet Gynecol 2014;3:268-9. 